\title{
Overexpression of the hyperplasia suppressor gene inactivates airway fibroblasts obtained from a rat model of chronic obstructive pulmonary disease by inhibiting the Wnt signaling pathway
}

\author{
ZHENGHANG GE $^{1 *}$, YI YANG $^{1 *}$, XUN ZHOU $^{1}$, JUN ZHANG $^{1}$, BO LI $^{1}$, XINXING WANG $^{2}$ and XIAN LUO \\ Departments of ${ }^{1}$ Respiratory Medicine, and ${ }^{2}$ Research and Teaching, The Second Affiliated Hospital of \\ Guizhou College of Traditional Chinese Medicine, Guiyang, Guizhou 550003, P.R. China
}

Received November 8, 2018; Accepted May 22, 2019

DOI: $10.3892 / \mathrm{mmr} .2019 .10504$

\begin{abstract}
The present study aimed to investigate the effects of hyperplasia suppressor gene (HSG) overexpression on the activation of airway fibroblasts in a rat model of chronic obstructive pulmonary disease (COPD) and assess the underlying molecular mechanisms. The rat model of COPD was established by injection of papain and confirmed by hematoxylin and eosin staining. Airway fibroblasts were identified using immunofluorescence, and HSG expression was facilitated by an HSG vector. Cell viability, apoptosis and the levels of matrix metallopeptidase-9 (MMP-9), platelet-derived growth factor (PDGF), and transforming growth factor- $\beta 1$ (TGF- $\beta 1$ ) were measured via Cell Counting Kit-8, flow cytometry and ELISA analyses, respectively, and potential mechanisms were detected by reverse transcription-quantitative polymerase chain reaction and western blotting. Airway fibroblasts from COPD rats were isolated and identified based on vimentin expression. Compared with the control group, HSG overexpression reduced cell viability, promoted apoptosis, and reduced the protein levels of TGF- $\beta 1$, MMP-9 and PDGF. Additionally, HSG overexpression reduced $\beta$-catenin and Ras homology family member A (RhoA) expression at both the mRNA and protein levels. Conversely, Wnt signaling pathway agonists lithium chloride $(\mathrm{LiCl})$ and 4-ethyl-5,6-dihydro-5-methyl(1,3)dioxolo(4,5-j)phenanthridine (HLY78), significantly reduced the effects of $\mathrm{HSG}$ overexpression $(\mathrm{P}<0.05$ vs. HSG). Cell viability in the $\mathrm{HSG}+\mathrm{LiCl}$ and $\mathrm{HSG}+\mathrm{HLY} 78$ groups
\end{abstract}

Correspondence to: Dr Zhenghang Ge, Department of Respiratory Medicine, The Second Affiliated Hospital of Guizhou College of Traditional Chinese Medicine, 32 Feishan Street, Guiyang, Guizhou 550003, P.R. China

E-mail: gzxtyk@sina.com

*Contributed equally

Key words: hyperplasia suppressor gene, airway fibroblasts, apoptosis, Wnt signaling pathway was increased, whereas apoptosis was reduced compared with HSG treatment alone. The protein levels of TGF- $\beta 1$, MMP-9 and PDGF were also decreased in the HSG + $\mathrm{LiCl}$ and HSG + HLY78 groups compared with the HSG group $(\mathrm{P}<0.05)$. Furthermore, the expression of $\beta$-catenin and RhoA was higher in the $\mathrm{HSG}+\mathrm{LiCl}$ and $\mathrm{HSG}+\mathrm{HLY} 78$ groups compared with the HSG group $(\mathrm{P}<0.05)$. Collectively, the results indicated that HSG overexpression inactivated airway fibroblasts from COPD by inhibiting the Wnt signaling pathway.

\section{Introduction}

Chronic obstructive pulmonary disease (COPD) is a common respiratory disease characterized by incomplete reversibility of airflow obstruction. The pathological changes occurring in COPD include airway reconstruction and pulmonary artery reconstruction, particularly chronic bronchitis and emphysema (1). Airway remodeling is a key step in regulating disease progression, whereas uncontrollable activation of fibroblasts is central to airway reconstruction $(1,2)$. As previously documented, factors including matrix metalloproteinase-9 (MMP-9), platelet-derived growth factor (PDGF) and transforming growth factor- $\beta 1$ (TGF- $\beta 1)$ are notably involved in airway remodeling (3-5).

The hyperplasia suppressor gene (HSG) can inhibit cell proliferation and the cell cycle $(6,7)$. HSG is reportedly highly expressed in normal cells, with reduced expression in proliferating cells (8-10). Overexpression of HSG can inhibit the malignant phenotype of breast cancer (11) and induce apoptosis in tumor cells (10). Of note, recombinant HSG can suppress the proliferation, and induce the apoptosis of airway fibroblasts (12); however, whether HSG is a suppressor of airway fibroblasts, and the underlying mechanisms involved in this process are yet to be verified.

The Wnt signaling pathway is involved not only in lung development, but also in the pathogenesis of pulmonary fibrosis (13), idiopathic pulmonary hypertension (14) and pulmonary interstitial disease (15). The Wnt/ $\beta$-catenin signaling pathway is required for cell differentiation, apoptosis, carcinogenesis, immunity, and other physiological and pathological processes $(16,17)$ and provides targets for the development of 
novel therapeutics to intervene with the development of COPD. The molecular mechanisms underpinning the pathogenesis of Wnt signaling components, including the destructive complex, in COPD are unclear (18); however, its role in cardiac and liver fibrosis has previously been explored $(19,20)$. As both the HSG and Wnt signaling pathways contribute to fibrosis, it remains unclear whether HSG may regulate the Wnt/ $\beta$-catenin signaling pathway in airway reconstruction. In the present study, an HSG overexpression vector was constructed to transfect airway fibroblasts in vitro to verify the effect of HSG overexpression on activation of airway fibroblasts, and assess the underlying mechanisms.

\section{Materials and methods}

Animals. A total of 20 male Sprague-Dawley rats (age, 3 months; body weight, $250 \mathrm{~g}$ ) were purchased from Hunan Slake Jingda Laboratory Animal Co., Ltd. [license no. SCXK (Hunan) 2016-0002]. All animals were raised in non-toxic plastic boxes, stainless steel wire cages and metal cages, and housed in a specific pathogen-free environment that was automatically maintained at a temperature of $22 \pm 2^{\circ} \mathrm{C}$ and a relative humidity of 45-65\%, under a controlled 12-h light/dark cycle with access to food and water ad libitum. All animal experiments were approved by the Ethics Committee of Guizhou College of Traditional Chinese Medicine (Guiyang, China).

Establishment of a rat model of COPD. Following anesthesia with sodium pentobarbital (40 mg/kg, intraperitoneal), rat skins were disinfected with iodophor. The epidermis and muscles along the middle of the neck were cut using surgical scissors to expose the trachea. Papain solution $(2 \mathrm{mg} / \mathrm{ml})$ was injected into the trachea at a dose of $1 \mathrm{ml} / \mathrm{kg}$ from top to bottom to reach the lungs. Subsequently, the animals were picked up and rotated to ensure that the drug had fully entered the trachea. Thereafter, the wound was sutured, and the animals were placed on an electric blanket. The animals were anesthetized with isoflurane (1\% in oxygen) and decapitated 8 days after remodeling. Airway tissues from 3 animals were collected on ice and fixed in $4 \%$ paraformaldehyde overnight at $4^{\circ} \mathrm{C}$. The tissues were sectioned into $5-\mu \mathrm{m}$ thick sections and mounted on slides, followed by hematoxylin and eosin staining for $5 \mathrm{~min}$ at room temperature. The stained sections were observed under a light microscope (magnification: x200; BX51; Olympus Corporation).

Preparation of airway fibroblasts. A total of 12 rats were sacrificed and thoracotomized under aseptic conditions to collect airway fibroblasts as previously described (21). A sterile scalpel was used to collect the tissue surrounding the airway; freshly obtained airway tissue from COPD rats was washed five times with phosphate-buffered saline (PBS) on an aseptic worktable. The tissue was then cut into $2 \times 2-\mathrm{mm}$ pieces using sterilized ophthalmic scissors. The tissue was pasted into the culture plate, and placed in a $5 \% \mathrm{CO}_{2}$ incubator at $37^{\circ} \mathrm{C}$ for $4 \mathrm{~h}$. After cell adherence, freshly prepared medium containing DMEM (Gibco; Thermo Fisher Scientific, Inc.) and $10 \%$ fetal bovine serum (FBS; cat. no. 04-007-1A; Biological Industries) was added to the culture plate, and the cells were further cultured in a $5 \% \mathrm{CO}_{2}$ incubator at $37^{\circ} \mathrm{C}$. Cell growth was monitored, the cell supernatant was periodically discarded, and newly prepared DMEM $+10 \%$ FBS culture medium was added into the culture dish.

Immunohistochemistry. The cultured dishes $\left(3 \times 10^{3} / \mathrm{ml}\right)$ were rinsed three times in PBS ( $3 \mathrm{~min} / \mathrm{wash}$ ), fixed in $4 \%$ paraformaldehyde for $15 \mathrm{~min}$ at room temperature, and permeated with $0.5 \%$ Triton X-100 PBS for $20 \mathrm{~min}$ at room temperature. Bovine serum albumin (5\%; Gibco; Thermo Fisher Scientific, Inc.) was added to the culture dish, which was subsequently sealed at $37^{\circ} \mathrm{C}$ for $30 \mathrm{~min}$. Anti-vimentin antibody (1:250; cat. no. ab92547; Abcam) was added to the dish and incubated at $37^{\circ} \mathrm{C}$ for $3 \mathrm{~h}$. The diluted $\mathrm{Cy} 3$-conjugated secondary antibody (1:200, cat. no. BA1032, Wuhan Boster Biological Technology, Ltd.) was added and incubated at $37^{\circ} \mathrm{C}$ for $30 \mathrm{~min}$. Subsequently, DAPI was used to stain the nuclei for $3 \mathrm{~min}$ at room temperature, and the images were observed under a fluorescence microscope (magnification: x200) as previously described (22).

Reverse transcription-quantitative polymerase chain reaction $(R T-q P C R)$. Airway fibroblasts $\left(3 \times 10^{3}\right.$ cells/well $)$ were seeded in 6-well plates. Following transfection and/or treatment, total mRNA was extracted using a TRIzol ${ }^{\circledR}$ assay kit (Baosheng Science \& Technology Innovation Co. Ltd.). RNA quality was evaluated based on the optical density (260/280 nm). mRNA was transcribed into cDNA using a SMART ${ }^{\circledR}$ MMLV Reverse Transcriptase kit (cat. no. 639522; Takara Biotechnology Co., Ltd.) at $37^{\circ} \mathrm{C}$ using the following thermocycling conditions: $25^{\circ} \mathrm{C}$ for $10 \mathrm{~min}, 37^{\circ} \mathrm{C}$ for $120 \mathrm{~min}$ and $85^{\circ} \mathrm{C}$ for $5 \mathrm{~min}$, which was subsequently used as the template for fluorescent qPCR. The reaction mixture included the following components: Deionized water $(9.5 \mu \mathrm{l})$, cDNA $(1 \mu \mathrm{l})$, primers $(2 \mu \mathrm{l})$ and $2 \mathrm{X}$ UltraSYBR Mixture (12.5 $\mu \mathrm{l}$; HY-K0501; MedChemExpress LLC) under the following cycling conditions: 35 cycles of $94^{\circ} \mathrm{C}$ denaturation for $45 \mathrm{sec}, 59^{\circ} \mathrm{C}$ annealing for $45 \mathrm{sec}$ and $72^{\circ} \mathrm{C}$ extension for $60 \mathrm{sec}$. The relative mRNA expression of HSG, $\beta$-catenin and Ras homology family member A (RhoA) was calculated using GAPDH as the reference using the $2^{-\Delta \Delta C q}$ method (23). The primers used in the study are presented in Table I.

Experimental groups. Airway fibroblasts were divided into nine groups: Control, vector, HSG overexpression (HSG), lithium chloride $(\mathrm{LiCl})$, vector $+\mathrm{LiCl}$, $\mathrm{HSG}+\mathrm{LiCl}$, 4-ethyl-5,6-dihydro-5-methyl-(1,3)dioxolo(4,5-j)phenanthridine (HLY78), vector + HLY78, and HSG + HLY78 (Fig. 1A). Wnt signaling pathway agonists, $\mathrm{LiCl}$ (cat. no. B6083) and HLY78 (cat. no. C5433) were purchased from Apexbio Technology, LLC. The cells were treated with either $10 \mathrm{mM} \mathrm{LiCl}$ or $10 \mu \mathrm{M}$ HLY78 for $24 \mathrm{~h}$, at $48 \mathrm{~h}$ at $37^{\circ} \mathrm{C}$ following transfection with the HSG vector.

Cell transfection. The HSG gene sequence (NM_130894) was obtained from the National Centre for Biotechnology Information database, and a biosynthetic gene fragment was cloned into the pCDNA3.1 (+) vector (Shanghai GenePharma Co. Ltd.) at the digestion site (Hind III/Xho I). Cells at $60 \%$ confluence were transfected with empty vector or HSG $(1 \mu \mathrm{g} / \mathrm{ml})$ using Lipofectamine ${ }^{\circledR} 3000$ (Invitrogen; Thermo 
Table I. Primer sequences.

\begin{tabular}{llccc}
\hline Gene name & \multicolumn{1}{c}{ Primer sequences $\left(5^{\prime}-3^{\prime}\right)$} & Primer length $(\mathrm{bp})$ & Product length (bp) & Annealing temperature $\left({ }^{\circ} \mathrm{C}\right)$ \\
\hline HSG F & AACTCCATCGTCACCGTCAA & 20 & 385 & 59 \\
HSG R & CAACCCGCAGGAAGCAA & 17 & 181 & 59 \\
RhoA F & AGAGTTGGCTTTATGGGACAC & 21 & 451 & 59 \\
RhoA R & GATGATGGGCACATTTGGA & 19 & 19 & \\
$\beta$-catenin F & TTATGAGTGGGAGCAAGGC & 19 & 141 \\
$\beta$-catenin R & ACAACGGGCTGTTTCTACG & 18 & 59 \\
GAPDH F & GCAAGTTCAACGGCACAG & 19 & & \\
GAPDH R & CGCCAGTAGACTCCACGAC & &
\end{tabular}

HSG, hyperplasia suppressor gene; RhoA, Ras homology family member A; F, forward; R, reverse.

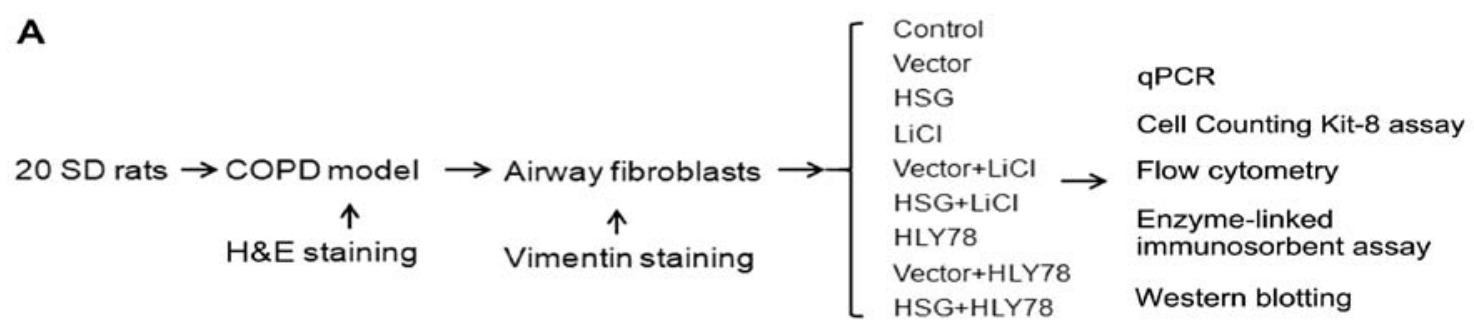

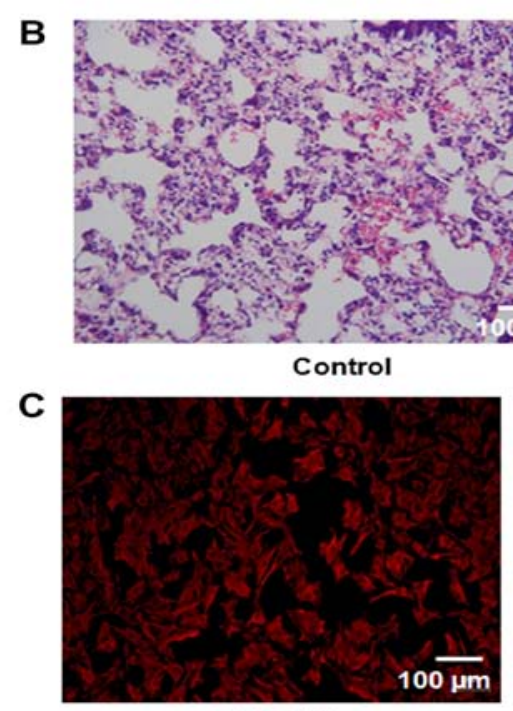

Vimentin

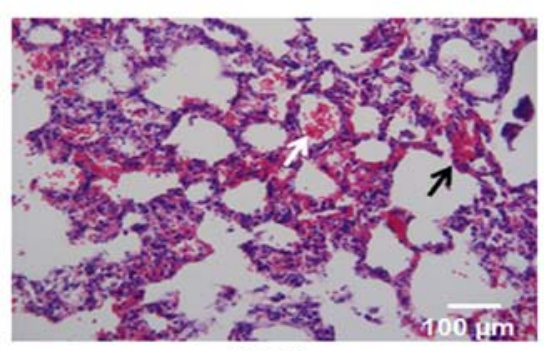

COPD

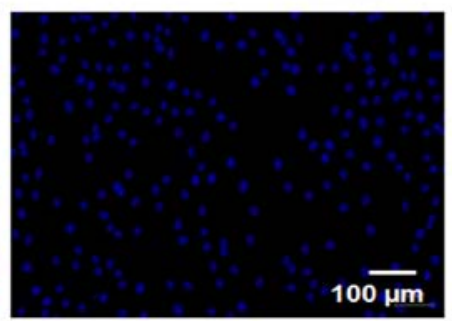

DAPI

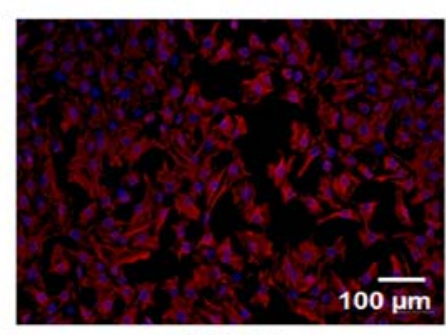

Merged

Figure 1. Airway fibroblasts collected from COPD rats. (A) Schematic illustration of the study design. (B) H\&E staining of the airway tissue. Black and white arrows indicate infiltration of inflammatory cells and exfoliation, respectively. (C) Identification of airway fibroblasts (magnification, $\mathrm{x} 200$ ). Red represents vimentin expression; blue represents nuclear staining (DAPI). COPD, chronic obstructive pulmonary disease; HSG, hyperplasia suppressor gene; LiCl, lithium chloride; HLY78, 4-ethyl-5,6-dihydro-5-methyl-(1,3)dioxolo(4,5-j)phenanthridine; qPCR, quantitative polymerase chain reaction; SD, Sprague-Dawley; H\&E, hematoxylin and eosin.

Fisher Scientific, Inc.). After $6 \mathrm{~h}$, the medium was replaced with fresh DMEM containing $10 \%$ FBS and cultured in a 5\% $\mathrm{CO}_{2}$ incubator at $37^{\circ} \mathrm{C}$ for $48 \mathrm{~h}$. The cells were then used in the following experiments.

Cell Counting Kit- 8 assay. After discarding the culture medium, the cells $\left(3 \times 10^{5} / \mathrm{ml}\right)$ were washed with PBS and digested with trypsin for 2-3 min. Next, the cells were resuspended, inoculated into 96 -well plates and placed in a $5 \%$ $\mathrm{CO}_{2}$ incubator at $37^{\circ} \mathrm{C}$ for $24 \mathrm{~h}$. The assay was performed as previously described (24). The optical density was determined using a microplate reader (Bio-Tek Instruments, Inc.) at $570 \mathrm{~nm}$ to determine cell viability.

Flow cytometry. The cells $\left(3 \times 10^{5} / \mathrm{ml}\right)$ were incubated in the dark with Annexin V-fluorescein isothiocyanate and propidium iodide (cat. no. AP101-100; Multisciences Biotech Co., Ltd.) for $30 \mathrm{~min}$ at room temperature. Subsequently, apoptosis was detected using a flow cytometer (BD Biosciences) within $1 \mathrm{~h}$. Totally, four quadrants were divided based upon the 
fluorescence intensity and analyzed using FlowJo v10 (FlowJo, LLC). Quadrant Q2-2 was added to box quadrant Q2-4 to obtain the percentage of apoptotic cells.

ELISA. The cells were collected and total protein was isolated using a triple prep kit (cat. no. 28-9425-44, ReadyPrep; GE Healthcare Life Sciences). Protein concentration was measured using a bicinchoninic acid assay kit (cat. no. P0009: Beyotime Institute of Biotechnology). Volumes were adjusted to normalize the protein content, and then aliquots were processed for the ELISA using rat TGF- $\beta 1$ (cat. no. MM-0181R1), rat MMP-9 (cat. no. MM-20918R1) and rat PDGF assay kits (cat. no. MM-0076R1; all MlBio; Shanghai Enzyme Biotechnology Co., Ltd.).

Western blot analysis. Following transfection and/or treatment as aforementioned, protein was extracted from each group using a protein isolation kit (cat. no. 28-9425-44; GE Healthcare Life Sciences). Protein levels were quantified with a bicinchoninic acid protein assay kit (cat. no. P0009; Beyotime Institute of Biotechnology). Proteins ( $25 \mu \mathrm{g} / \mathrm{lane}$; $0.5 \mu \mathrm{g} / \mu \mathrm{l})$ were separated via $12 \%$ SDS-PAGE and transferred onto polyvinylidene fluoride membranes. The membranes were blocked in 5\% skimmed milk for $2 \mathrm{~h}$ at room temperature and incubated with the following primary antibodies overnight at $4^{\circ} \mathrm{C}$ : Mouse monoclonal anti-GAPDH $(1: 2,000$; cat. no. TA-08; OriGene Technologies, Inc.); rabbit polyclonal anti-HSG (1:5,000; cat. no. ab124773; Abcam); rabbit polyclonal anti- $\beta$-catenin (1:300; cat. no. ab32572; Abcam) and rabbit polyclonal anti-RhoA (1:2,000; cat. no. ab187026; Abcam). The IgG horseradish peroxidase-conjugated secondary antibody (mouse: 1:100; cat. no. ab131368; Abcam; rabbit: 1:100; ZB-2301; OriGene Technologies, Inc.) was added and co-incubated for $2 \mathrm{~h}$ at room temperature. An enhanced chemiluminescence exposure liquid droplet (cat. no. RJ239676; Thermo Fisher Scientific, Inc.) was added to the membranes. The membranes were visualized using a gel imaging system (Bio-Rad Laboratories, Inc.). Densitometry was performed using Quantity One version 1.4.6 (Bio-Rad Laboratories, Inc.).

Statistical analysis. Data were presented as the mean \pm standard error of the mean with 6 independent repeats and analyzed using SPSS version 17.0 (SPSS, Inc.). Significant differences were determined using one-way analysis of variance, followed by the Student-Newman-Keuls post hoc test. $\mathrm{P}<0.05$ was considered to indicate a statistically significant difference.

\section{Results}

HSG overexpression reduces the viability of airway fibroblasts. The airway tissue of the control group exhibited regular alveolar structure (Fig. 1B). Pathological expansion and fusion of alveolar cavities were not observed. The wall of the bronchial tube was normal, the epithelium of the airway mucosa was smooth, cilia were neatly arranged, and obvious inflammatory exudation was not found in the tracheal cavity. In contrast, the airway tissue of the COPD group showed evidence of emphysema, alveolar dilatation, an alveolar wall that disintegrated and fused to form lung ulcers, and markedly decreased numbers of alveoli (Fig. 1B). The
A
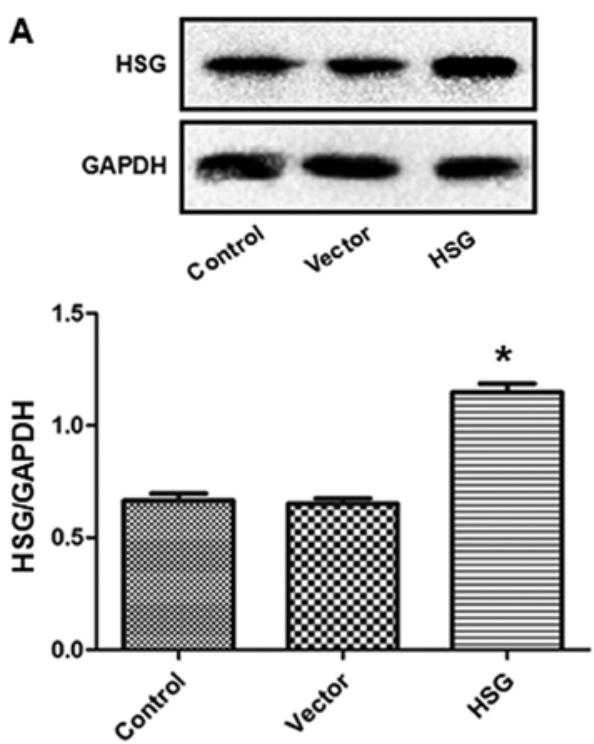

B

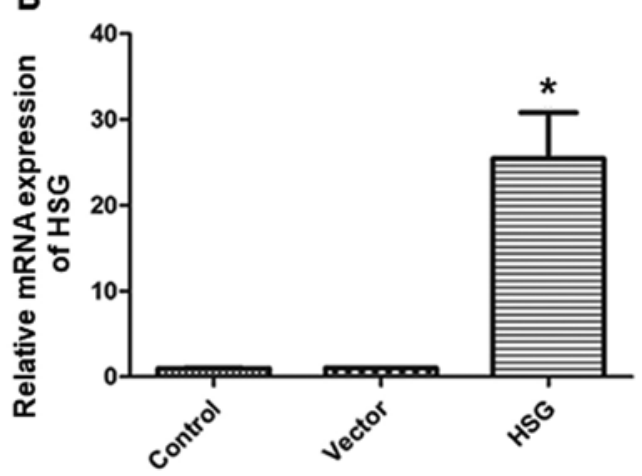

Figure 2. HSG vector promotes HSG expression in airway fibroblasts. (A) Protein expression of HSG. (B) mRNA expression of HSG. * $\mathrm{P}<0.05$ vs. Vector. HSG, hyperplasia suppressor gene; $\mathrm{LiCl}$, lithium chloride.

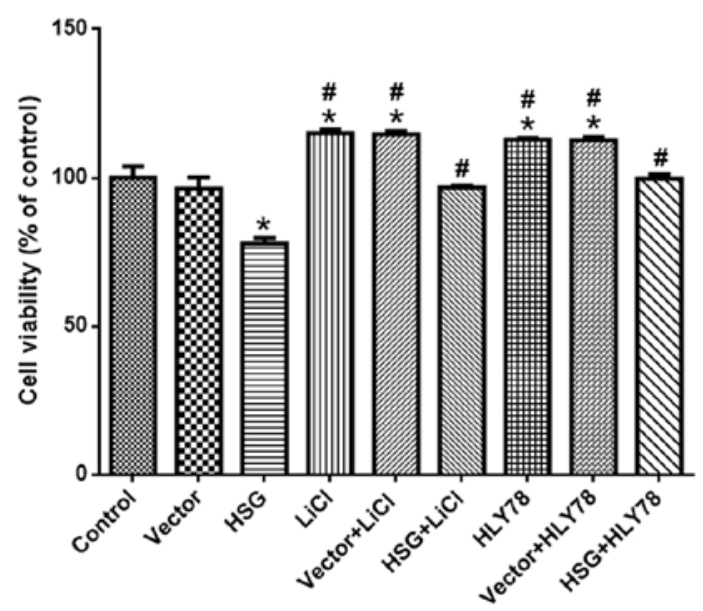

Figure 3. HSG overexpression reduces cell viability of airway fibroblasts. Cell viability was measured using a Cell Counting Kit- 8 assay. ${ }^{*} \mathrm{P}<0.05$ vs. Vector; ${ }^{\#} \mathrm{P}<0.05$ vs. HSG. HSG, hyperplasia suppressor gene; $\mathrm{LiCl}$, lithium chloride; HLY78, 4-ethyl-5,6-dihydro-5-methyl-(1,3)dioxolo(4,5-j)phenanthridine.

goblet cells of the bronchial epithelium showed proliferation, and a number of inflammatory cells such as neutrophils and giant cells infiltrated the lumen, accompanied by the proliferation of fibrous connective tissue. 

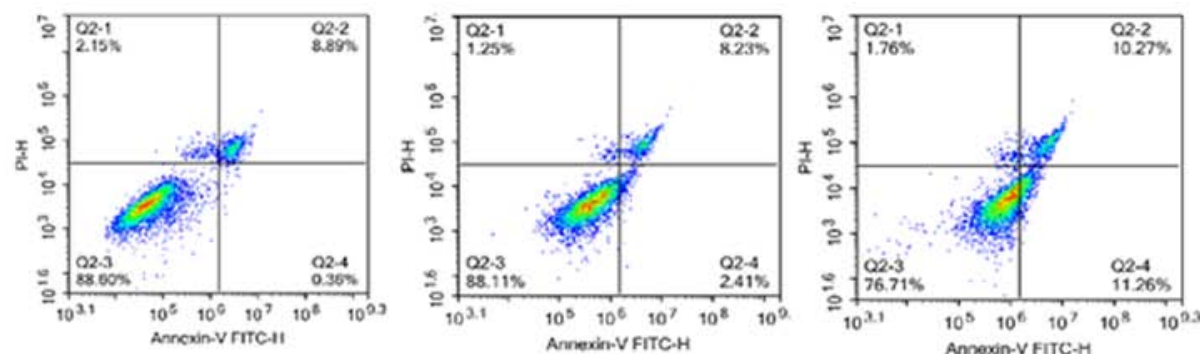

Control

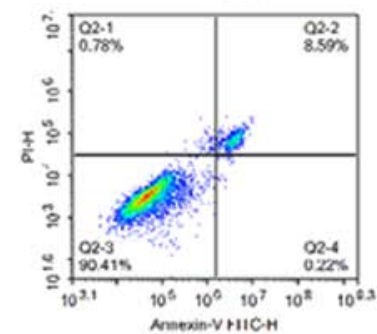

Vector

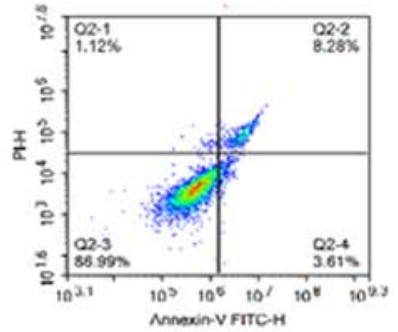

HSG
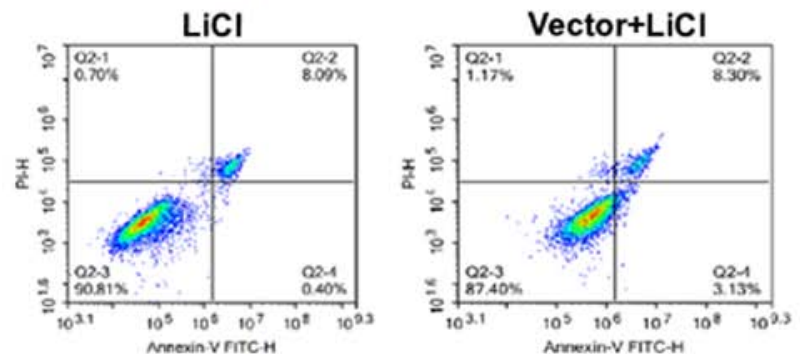

HLY78

Vector+HLY78
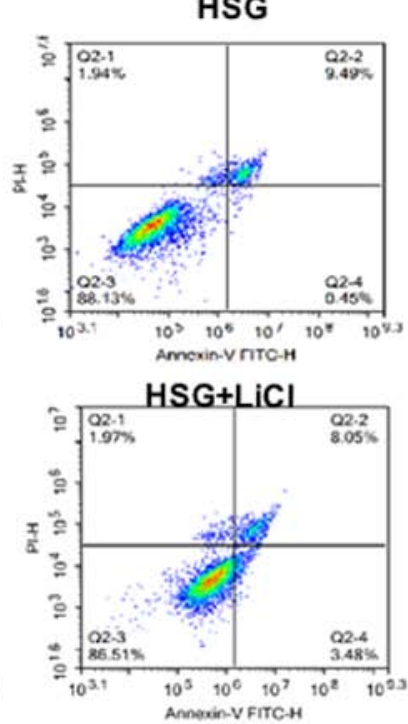

HSG+HLY78

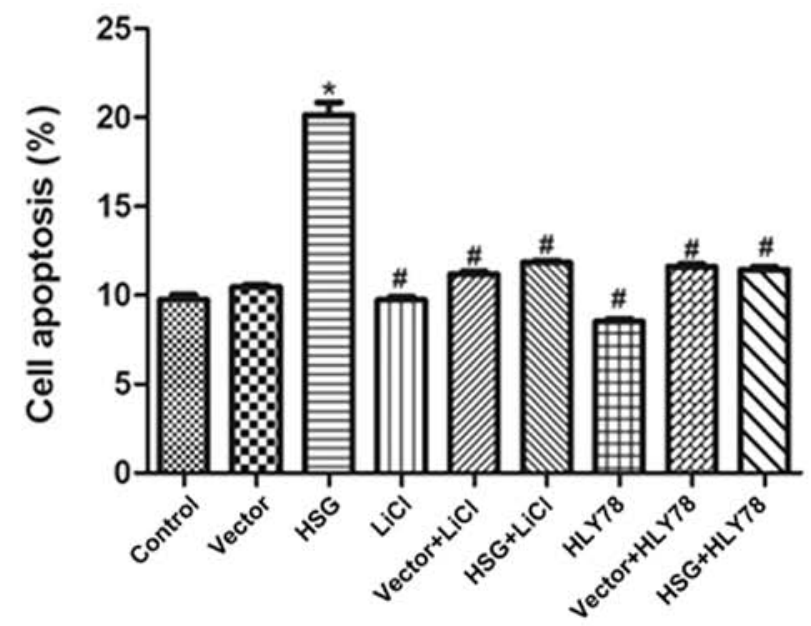

Figure 4. HSG overexpression facilitates the apoptosis of airway fibroblasts from chronic obstructive pulmonary disease rats. Apoptosis was measured using flow cytometry. ${ }^{~} \mathrm{P}<0.05$ vs. Vector; ${ }^{\#} \mathrm{P}<0.05$ vs. HSG. HSG, hyperplasia suppressor gene; LiCl, lithium chloride; HLY78, 4-ethyl-5,6-dihydro-5-methyl-(1,3) dioxolo(4,5-j)phenanthridine; PI, propidium iodide.

The identification of airway fibroblasts is shown in Fig. 1C, wherein red indicates vimentin expression, and nuclear staining by DAPI is observed in blue. All cells showed vimentin expression, indicating successful preparation of the airway fibroblasts. Compared with the vector group, the HSG vector upregulated HSG expression at both the mRNA and protein levels (both $\mathrm{P}<0.05$; Fig. $2 \mathrm{~A}$ and $\mathrm{B}$ ), whereas the control vector did not influence HSG expression. Thereafter, the effects of HSG overexpression on cell viability were measured. The cell viability of the HSG group was decreased (vs. vector, $\mathrm{P}<0.05$ ), which was inhibited by HLY78 and $\mathrm{LiCl}$ (vs. HSG, P<0.05;
Fig. 3). Of note, $\mathrm{LiCl}$ and HLY78 alone increased cell viability (vs. control, $\mathrm{P}<0.05$ ).

HSG overexpression facilitates apoptosis of airway fibroblasts. To further examine the effects of HSG overexpression on apoptosis, flow cytometry was used to detect the cell distribution following double staining. The apoptosis rate in the HSG group was significantly higher compared with that observed in the vector group $(\mathrm{P}<0.05 ; \mathrm{Fig}$. 4). $\mathrm{LiCl}$ and $\mathrm{HLY} 78$ reduced the effects of HSG overexpression on apoptosis (vs. HSG, $\mathrm{P}<0.05$ ). The rates of apoptosis in the HSG + $\mathrm{LiCl}$ and HSG + HLY78 
groups were significantly lower compared with that detected in the HSG group $(\mathrm{P}<0.05)$. However, $\mathrm{LiCl}$ and HLY78 alone did not affect apoptosis (vs. control, P $>0.05$; Fig. 4).

$H S G$ overexpression reduces the levels of TGF- $\beta 1, M M P-9$, and PDGF. The protein levels of TGF- $\beta 1$, MMP-9, and PDGF in each group are shown in Fig. 5. The levels of TGF- $\beta 1$ (Fig. 5A), MMP-9 (Fig. 5B), and PDGF (Fig. 5C) in the HSG group were decreased compared with in the control group. In contrast, these levels were higher in the $\mathrm{HSG}+\mathrm{LiCl}$ and HSG + HLY78 groups compared with the HSG group $(\mathrm{P}<0.05) . \mathrm{LiCl}$ and HLY78 alone also increased the levels of TGF- $\beta 1$, MMP-9, and PDGF (vs. control; P<0.05).

$H S G$ overexpression reduces the expression of $\beta$-catenin and $R h o A$. The expression of $\beta$-catenin and RhoA in each group was normalized to GAPDH and is presented in Fig. 6. The mRNA levels of $\beta$-catenin (Fig. 6A) and RhoA (Fig. 6B) were higher in the HSG group compared with the vector group (both $\mathrm{P}<0.05$ ). However, the expression of $\beta$-catenin and RhoA was reduced by $\mathrm{LiCl}$ and HLY78, respectively (vs. HSG, $\mathrm{P}<0.05$ ). The protein expression of $\beta$-catenin (Fig. 6C) and RhoA (Fig. 6D) was also detected using western blot analysis. Consistent with the mRNA expression, the protein levels of $\beta$-catenin and RhoA (normalized to GAPDH) in the HSG group were higher (vs. control, $\mathrm{P}<0.05$ ), and the expression of $\beta$-catenin and RhoA was reduced by $\mathrm{LiCl}$ and $\mathrm{HLY} 78$, respectively (vs. HSG, P<0.05). The expression of $\beta$-catenin and RhoA was promoted by $\mathrm{LiCl}$ and HLY78 alone, respectively (vs. control, $\mathrm{P}<0.05$ ).

\section{Discussion}

Although the effects of HSG on tumors are well documented $(10,11)$, the role of HSG in airway fibroblast proliferation in COPD remains unknown. The present study demonstrated that HSG overexpression reduced cell viability and facilitated the apoptosis of airway fibroblasts in a rat model of COPD. This mechanism involved inactivation of the Wnt signaling pathway. These data may have important implications for the treatment of airway remodeling in the future.

The pathogenesis of COPD is closely associated with factors, including smoking, exposure to air pollution and inhalation of dust $(25,26)$. Pathological changes observed in COPD include chronic bronchitis, emphysema, airway reconstruction and pulmonary artery reconstruction (27). In the present study, the alveolar wall became thinner, the number of alveolar septa was markedly reduced, the alveolar cavity was enlarged and ruptured, and lung ulcers formed following inhalation of papain. A previous study reported that exogenous recombinant HSG may inhibit cell proliferation and airway reconstruction (12). In the present study, it was further reported that an exogenous HSG vector may reduce the viability, and promote the apoptosis of airway fibroblasts. Collectively, these studies indicated the importance of HSG as a potential target for the treatment of airway remodeling in patients with COPD.

In the respiratory system, the Wnt signaling pathway participates in the development of lung tissue and is involved in pulmonary fibrosis (28). In the present study, activators of the $\mathrm{Wnt} / \beta$-catenin signaling pathways were used to confirm the role of these pathways in the HSG-induced decrease in
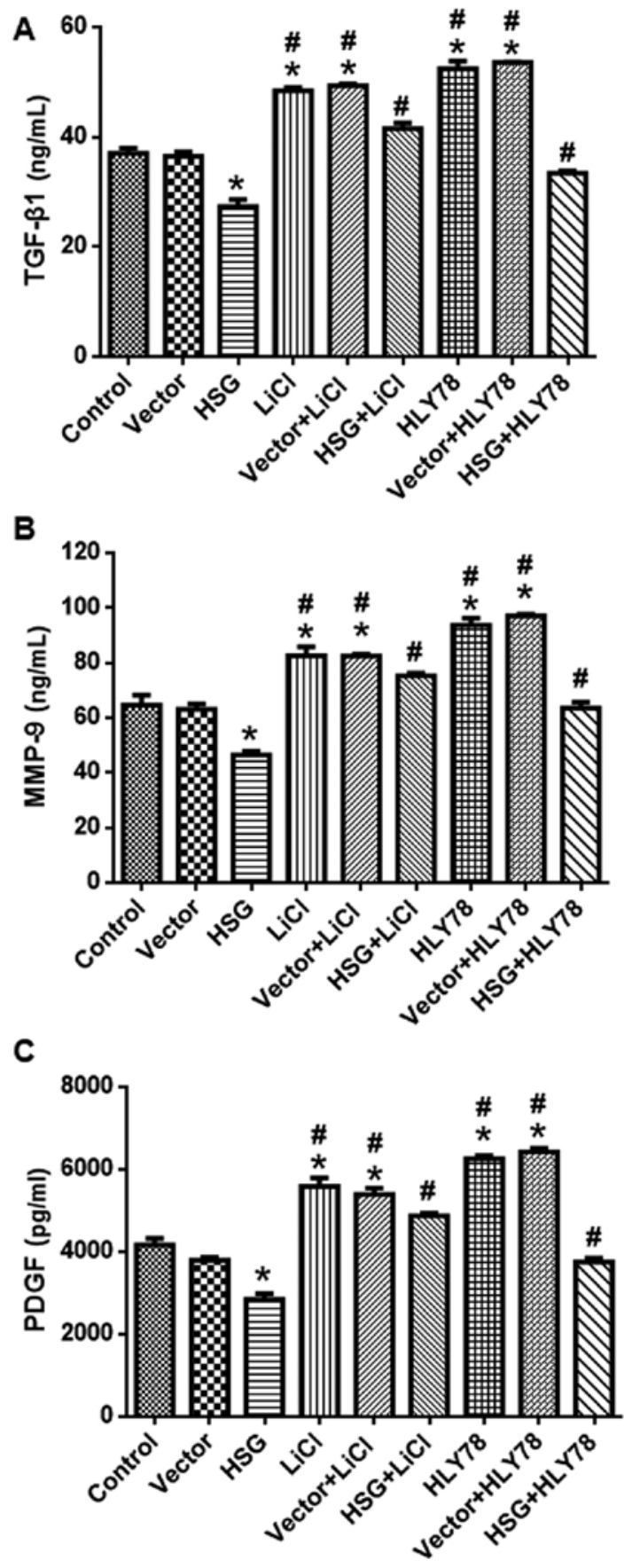

Figure 5. HSG overexpression reduces the protein levels of (A) TGF- $\beta 1$, (B) MMP-9 and (C) PDGF as determined via ELISA. ${ }^{*} \mathrm{P}<0.05$ vs. Vector; ${ }^{\#} \mathrm{P}<0.05$ vs. HSG. HSG, hyperplasia suppressor gene; $\mathrm{LiCl}$, lithium chloride; HLY78, 4-ethyl-5,6-dihydro-5-methyl-(1,3)dioxolo(4,5-j)phenanthridine.

cell viability and increase in apoptosis. These results further indicated that Wnt signaling is involved in airway remodeling of COPD (29-32).

TGF- $\beta 1$ is a known target of the Wnt pathway and a multifunctional protein (33). It plays a role in cell growth, differentiation, apoptosis, and regulation of the immune system (34-36). TGF- $\beta 1$ is widely distributed in the trachea and bronchus, and found in infiltrating neutrophils, macrophages, and airway fibroblasts during the progression of COPD (37). It is the most important fibrogenic cytokine and can reverse-regulate and stimulate fibroblasts to synthesize and secrete components 

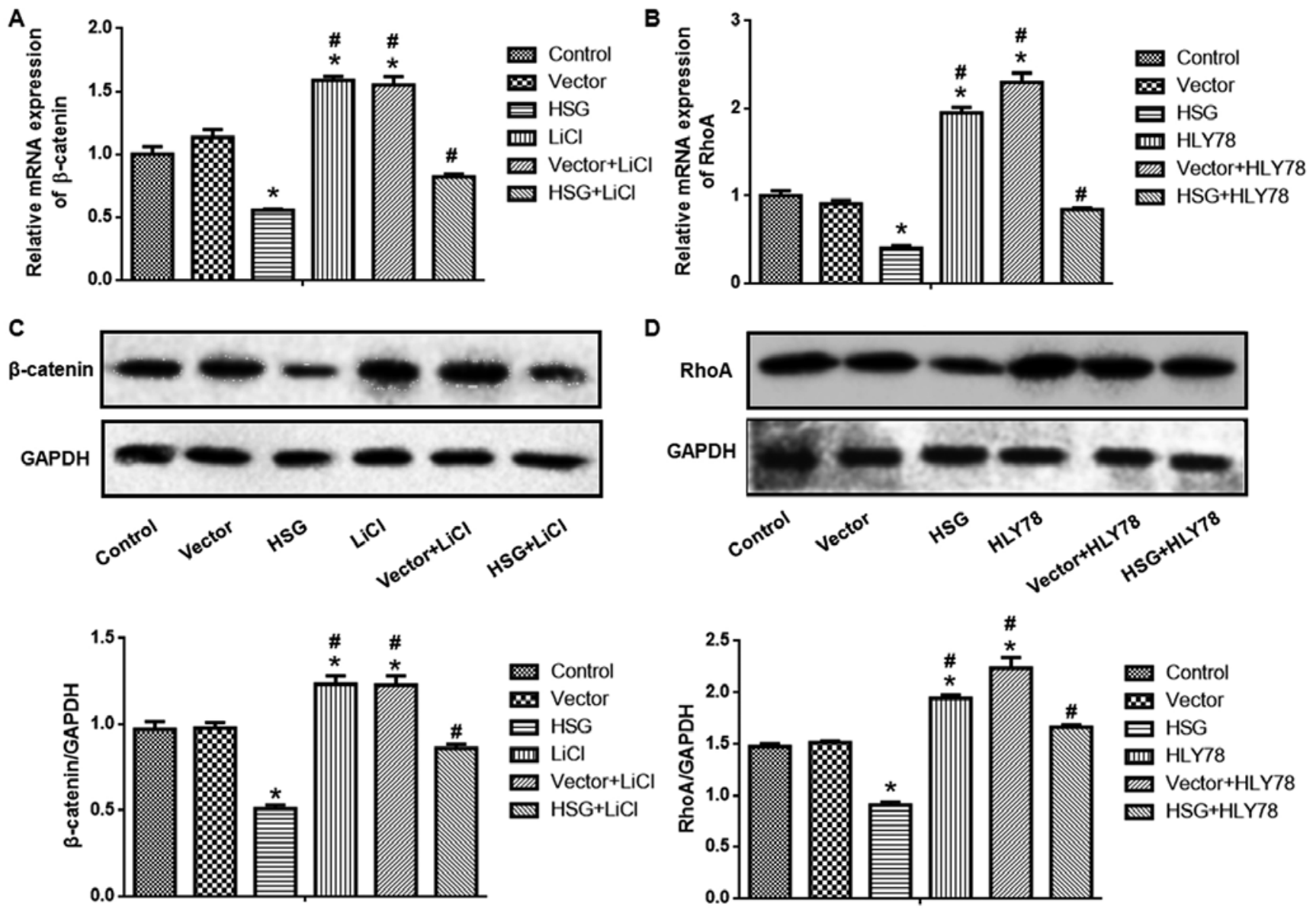

Figure 6. HSG overexpression reduces the expression of $\beta$-catenin and RhoA. mRNA expression of (A) $\beta$-catenin and (B) RhoA as determined via reverse transcription-quantitative PCR analysis. Protein expression of (C) $\beta$-catenin and (D) RhoA as determined via western blotting. ${ }^{*} \mathrm{P}<0.05$ vs. Vector; ${ }^{\prime \prime} \mathrm{P}<0.05$ vs HSG. HSG, hyperplasia suppressor gene; RhoA, Ras homology family member A; LiCl, lithium chloride; HLY78, 4-ethyl-5,6-dihydro-5-methyl-(1,3) dioxolo(4,5-j)phenanthridine.

of the extracellular matrix, leading to airway fibrosis (38-40). In the pathogenesis of COPD, MMP-9 mainly functions by degrading extracellular components of the alveolar matrix and aggravating alveolar cavity expansion, thereby resulting in decreased elasticity and low retraction (41). On the other hand, MMP-9 is involved in airway remodeling by destroying epithelial and endothelial cells (42). In addition, MMP-9 is a target of the Wnt pathway $(30,43)$. PDGF can stimulate the chemotaxis and proliferation of airway fibroblasts and extracellular matrix synthesis, one of the mechanisms of airway reconstruction (44). The results from the present study showed that HSG regulates the expression of TGF- $\beta 1$, MMP-9 and PDGF. Additionally, the expression of these factors was regulated by the Wnt/ $/$-catenin and $\mathrm{Wnt} / \mathrm{PCP}$ signaling pathways. These results suggested that HSG may interfere with airway remodeling in COPD.

Additionally, HSG can inhibit the expression of MMP-9, PDGF, TGF- $\beta 1$ in fibroblasts, thus inhibiting airway remodeling (45). These regulatory effects are mediated by the Wnt signaling pathway. In the present study HSG was negatively associated with the Wnt/ $\beta$-catenin and Wnt/PCP signaling pathways, which further confirmed the association between HSG and the Wnt signaling pathway. It can be concluded that HSG inhibits the proliferation of airway fibroblasts by inhibiting the abnormal activation of the Wnt signaling pathway.
Therefore, the promotion of HSG expression, or inhibition of abnormal activation of the Wnt/PCP signaling pathway to inhibit the overexpression of MMP-9, PDGF and TGF- $\beta 1$, may be an effective therapeutic strategy for airway remodeling in COPD. Although HSG overexpression inactivated the Wnt signaling pathway, the specific mechanisms could not be verified. A previous study demonstrated that PTEN, another tumor suppressor gene, interacts with Wnt1 to regulate the Wnt signaling pathway (46). Whether HSG is directly or indirectly linked to the Wnt signaling pathway requires further investigation.

The present study has certain limitations. First, the majority of the experiments were conducted in the cellular model, although airway fibroblasts were collected from COPD rats. In vivo experiments are required to confirm the present results. Second, an association was established between HSG and the Wnt signaling pathway in apoptosis; however, the exact mechanism of regulation requires further investigation. In addition, the contribution of autophagy and other types of cell death should also be determined in future studies.

In conclusion, our data demonstrated that HSG overexpression inactivates airway fibroblasts via regulation of the Wnt signaling pathway. This may represent a potential therapeutic target for COPD. 


\section{Acknowledgements}

Not applicable.

\section{Funding}

The present study was supported by the National Natural Science Foundation of China (grant no. 81473533) and the Major Basic Research in Guizhou Province [grant no. (2015) 2002].

\section{Availability of data and materials}

The datasets used during the present study are available from the corresponding author upon reasonable request.

\section{Authors' contributions}

$Z G$ and $Y Y$ conceived and designed the experiments; $Z G$, YY, XZ, JZ, BL, XW and XL performed the experiments and analyzed the data; ZG and YY wrote the manuscript. All authors read and approved the manuscript and agree to be accountable for all aspects of the research in ensuring that the accuracy or integrity of any part of the work are appropriately investigated and resolved.

\section{Ethics approval and consent to participate}

All animal experiments were approved by the Ethics Committee of Guizhou College of Traditional Chinese Medicine (Guiyang, China).

\section{Patient consent for publication}

Not applicable.

\section{Competing interests}

The authors declare that they have no competing interests.

\section{References}

1. Yu ZW, Xu YQ, Zhang XJ, Pan JR, Xiang HX, Gu XH, Ji SB and Qian J: Mutual regulation between miR-21 and the TGF $\beta /$ Smad signaling pathway in human bronchial fibroblasts promotes airway remodeling. J Asthma 56: 341-349, 2019.

2. Lai T, Tian B, Cao C, Hu Y, Zhou J, Wang Y, Wu Y, Li Z, Xu X, Zhang M, et al: HDAC2 suppresses IL17A-mediated airway remodeling in human and experimental modeling of COPD. Chest 153: 863-875, 2018

3. Ricciardolo FLM, Folkerts G, Folino A and Mognetti B: Bradykinin in asthma: Modulation of airway inflammation and remodelling. Eur J Pharmacol 827: 181-188, 2018.

4. Eapen MS, Myers S, Lu W, Tanghe C, Sharma P and Sohal SS sE-cadherin and sVE-cadherin indicate active epithelial/endothelial to mesenchymal transition (EMT and EndoMT) in smokers and COPD: Implications for new biomarkers and therapeutics. Biomarkers 23: 709-711, 2018.

5. Mahmood MQ, Reid D, Ward C, Muller HK, Knight DA, Sohal SS and Walters EH: Transforming growth factor (TGF) $\beta_{1}$ and Smad signalling pathways: A likely key to EMT-associated COPD pathogenesis. Respirology 22: 133-140, 2017.

6. Sun ZQ, Chen G, Guo Q, Li HF and Wang Z: In vivo and in vitro effects of hyperplasia suppressor gene on the proliferation and apoptosis of lung adenocarcinoma A549 cells. Biosci Reports 38: BSR20180391, 2018.
7. Luo L, Gong YQ, Qi X, Lai W, Lan H and Luo Y: Effect of tumor suppressor PTEN gene on apoptosis and cell cycle of human airway smooth muscle cells. Mol Cell Biochem 375: 1-9, 2013.

8. Jiang GJ, Han M, Zheng B and Wen JK: Hyperplasia suppressor gene associates with smooth muscle alpha-actin and is involved in the redifferentiation of vascular smooth muscle cells. Heart Vessels 21: 315-320, 2006.

9. Guo YH, Li Q, Yu HY and Gao W: Hyperplasia suppressor gene induces vascular smooth muscle cell apoptosis. Beijing Da Xue Xue Bao Yi Xue Ban 39: 394-398, 2007 (In Chinese).

10. Wu L, Li Z, Zhang Y, Zhang P, Zhu X, Huang J, Ma T, Lu T, Song Q, Li Q, et al: Adenovirus-expressed human hyperplasia suppressor gene induces apoptosis in cancer cells. Mol Cancer Ther 7: 222-232, 2008.

11. Zhang Y, Du Q, Qiu XY, Tian XX and Fang WG: Over expression of hyperplasia suppressor gene inhibits the malignant phenotype of breast cancer cell. Zhonghua Bing Li Xue Za Zhi 39: 259-263, 2010 (In Chinese).

12. Zheng-Xing GE, Bo LI, Zhou X and Chang LI: rHSG gene regulates airway fibroblast proliferation and apoptosis of COPD rats. Basic Clin Med 33: 1235-1241, 2013.

13. Villar J, Cabrera NE, Valladares F, Casula M, Flores C, Blanch L, Quilez ME, Santana-Rodríguez N, Kacmarek RM and Slutsky AS: Activation of the Wnt/ $\beta$-catenin signaling pathway by mechanical ventilation is associated with ventilator-induced pulmonary fibrosis in healthy lungs. PLoS One 6: e23914, 2011.

14. Chilosi M, Poletti V, Zamò A, Lestani M, Montagna L, Piccoli P, Pedron S, Bertaso M, Scarpa A, Murer B, et al: Aberrant Wnt/beta-catenin pathway activation in idiopathic pulmonary fibrosis. Am J Pathol 162: 1495-1502, 2003.

15. Königshoff M, Balsara N, Pfaff EM, Kramer M, Chrobak I, Seeger W and Eickelberg O: Functional Wnt signaling is increased in idiopathic pulmonary fibrosis. PLoS One 3: e2142, 2008.

16. Peng Y,Zhang X, Ma Q, Yan R, Qin Y, Zhao Y, Cheng Y, Yang M, Wang Q, Feng X, et al: MiRNA-194 activates the Wnt/ß-catenin signaling pathway in gastric cancer by targeting the negative Wnt regulator, SUFU. Cancer Lett 385: 117-127, 2017.

17. Clevers $H$ and Nusse $R$ : Wnt/ $\beta$-catenin signaling and disease. Cell 149: 1192-1205, 2012.

18. Qu J, Yue L, Gao J and Yao H: Perspectives on Wnt signal pathway in the pathogenesis and therapeutics in chronic obstructive pulmonary disease. J Pharmacol Exp Ther 369: 473-480, 2019.

19. Tao H, Yang JJ, Shi KH and Li J: Wnt signaling pathway in cardiac fibrosis: New insights and directions. Metabolism 65: 30-40, 2016.

20. Nishikawa K, Osawa $Y$ and Kimura K: Wnt/ $\beta$-catenin signaling as a potential target for the treatment of liver cirrhosis using antifibrotic drugs. Int J Mol Sci 19: E3103, 2018.

21. Lewis CC, Chu HW, Westcott JY, Tucker A, Langmack EL, Sutherland ER and Kraft M: Airway fibroblasts exhibit a synthetic phenotype in severe asthma. J Allergy Clin Immunol 115: 534-540, 2005

22. Song Z, Chen H, Xu W, Wu S and Zhu G: Basolateral amygdala calpain is required for extinction of contextual fear-memory. Neurobiol Learn Mem 155: 180-188, 2018.

23. Livak KJ and Schmittgen TD: Analysis of relative gene expression data using real-time quantitative PCR and the 2(-Delta Delta C(T)) method. Methods 25: 402-408, 2001.

24. Zhu G, Wang X, Wu S and Li Q: Involvement of activation of $\mathrm{PI} 3 \mathrm{~K} / \mathrm{Akt}$ pathway in the protective effects of puerarin against MPP+-induced human neuroblastoma SH-SY5Y cell death. Neurochem Int 60: 400-408, 2012.

25. Aigon A and Billecocq S: Prevalence and impact on quality of life of urinary incontinence in an adult population with chronic obstructive pulmonary diseases, literature review. Prog Urol 28: 962-972, 2018 (In French).

26. Oshagbemi OA, Keene SJ, Driessen JHM, Jordan R, Wouters EFM, de Boer A, de Vries F and Franssen FME: Trends in moderate and severe exacerbations among COPD patients in the UK from 2005 to 2013. Respir Med 144: 1-6, 2018.

27. Moon JY, Leitao Filho FS, Shahangian K, Takiguchi H and Sin DD: Blood and sputum protein biomarkers for chronic obstructive pulmonary disease (COPD). Expert Rev Proteomics 15: 923-935, 2018.

28. Reuter S, Beckert H and Taube C: Take the Wnt out of the inflammatory sails: Modulatory effects of Wnt in airway diseases. Lab Invest 96: 177-185, 2016.

29. Bartel S, Carraro G, Alessandrini F, Krauss-Etschmann S, Ricciardolo FLM and Bellusci S: miR-142-3p is associated with aberrant WNT signaling during airway remodeling in asthma. Am J Physiol Lung Cell Mol Physiol 315: L328-L333, 2018. 
30. Royer PJ, Henrio K, Pain M, Loy J, Roux A, Tissot A, Lacoste P, Pison C, Brouard S and Magnan A; COLT consortium: TLR3 promotes MMP-9 production in primary human airway epithelial cells through Wnt/ $\beta$-catenin signaling. Respir Res 18: 208, 2017.

31. Koopmans $\mathrm{T}$ and Gosens R: Revisiting asthma therapeutics: Focus on WNT signal transduction. Drug Discov Today 23: 49-62, 2018.

32. Hussain M, Xu C, Lu M, Wu X, Tang L and Wu X: Wnt/ $\beta$-catenin signaling links embryonic lung development and asthmatic airway remodeling. Biochim Biophys Acta Mol Basis Dis 1863: 3226-3242, 2017.

33. Vallée A, Lecarpentier Y, Guillevin R and Vallée JN: Interactions between TGF- $\beta 1$, canonical WNT/ $\beta$-catenin pathway and PPAR $\gamma$ in radiation-induced fibrosis. Oncotarget 8: 90579-90604, 2017.

34. Si Y, Bai J, Wu J, Li Q, Mo Y, Fang R and Lai W: LncRNA PlncRNA1 regulates proliferation and differentiation of hair follicle stem cells through TGFbetalmediated Wnt/betacatenin signal pathway. Mol Med Rep 17: 1191-1197, 2018.

35. Ma F, Li W, Liu C, Li W, Yu H, Lei B, Ren Y, Li Z, Pang D and Qian C: MiR-23a promotes TGF- $\beta 1$-induced EMT and tumor metastasis in breast cancer cells by directly targeting CDH1 and activating Wnt/ $\beta$-catenin signaling. Oncotarget 8: 69538-69550, 2017.

36. Li M, Yuan Y, Chen Q, Me R, Gu Q, Yu Y, Sheng M and Ke B: Expression of $\mathrm{Wnt} / \beta$-catenin signaling pathway and its regulatory role in type I collagen with TGF- $\beta 1$ in scleral fibroblasts from an experimentally induced myopia guinea pig model. J Ophthalmol 2016: 5126560, 2016.

37. Godinas L, Corhay JL, Henket M, Guiot J,Louis R and Moermans C: Increased production of TGF- $\beta 1$ from sputum cells of COPD Relationship with airway obstruction. Cytokine 99: 1-8, 2017.

38. Westergren-Thorsson G, Bagher M, Andersson-Sjoland A, Andersson-Sjöland A, Thiman L, Löfdahl CG, Hallgren O, Bjermer $\mathrm{L}$ and Larsson-Callerfelt AK: VEGF synthesis is induced by prostacyclin and TGF-beta in distal lung fibroblasts from COPD patients and control subjects: Implications for pulmonary vascular remodelling. Respirology 23: 68-75, 2018.

39. Chen H, Zhang R, Zheng Q, Yan X, Wu S and Chen Y: Impact of body mass index on long-term blood pressure variability: A cross-sectional study in a cohort of Chinese adults. BMC Public Health 18: 1193, 2018
40. Di Stefano A, Sangiorgi C, Gnemmi I, Casolari P, Brun P, Ricciardolo FLM, Contoli M, Papi A, Maniscalco P, Ruggeri $\mathrm{P}$, et al: TGF- $\beta$ signaling pathways in different compartments of the lower airways of patients with stable COPD. Chest 153: 851-862, 2018.

41. Zhdan VN, Potyazhenko MM, Khaymenova GS, Lyulka NN, Dubrovinskaya TV and Ivanitsky IV: Intensifying approach to the therapy of patients with constellation of the diseases: Chronic obstructive pulmonary disease and osteoarthritis. Wiad Lek 70: 578-580, 2017.

42. Zhao Y, Qiao X, Wang L, Tan TK, Zhao H, Zhang Y, Zhang J, Rao P, Cao Q, Wang Y, et al: Matrix metalloproteinase 9 induces endothelial-mesenchymal transition via Notch activation in human kidney glomerular endothelial cells. BMC Cell Biol 17: $21,2016$.

43. Yang Z, Li K, Liang Q, Zheng G, Zhang S, Lao X, Liang Y and Liao G: Elevated hydrostatic pressure promotes ameloblastoma cell invasion through upregulation of MMP-2 and MMP-9 expression via Wnt/ $\beta$-catenin signalling. J Oral Pathol Med 47: 836-846, 2018

44. Lu J, Zhu Y, Feng W, Pan Y, Li S, Han D, Liu L, Xie X, Wang $\mathrm{G}$ and $\mathrm{Li}$ M: Platelet-derived growth factor mediates interleukin-13-induced collagen I production in mouse airway fibroblasts. J Biosci 39: 693-700, 2014.

45. Song S,Zhang M, YiZ,Zhang H, Shen T, Yu X, Zhang C, Zheng X, Yu L, Ma C, et al: The role of PDGF-B/TGF- $\beta 1 /$ neprilysin network in regulating endothelial-to-mesenchymal transition in pulmonary artery remodeling. Cell Signal 28: 1489-1501, 2016.

46. Zhao H, Cui Y, Dupont J, Sun H, Hennighausen L and Yakar S: Overexpression of the tumor suppressor gene phosphatase and tensin homologue partially inhibits wnt-1-induced mammary tumorigenesis. Cancer Res 65: 6864-6873, 2005.

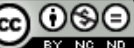

This work is licensed under a Creative Commons Attribution-NonCommercial-NoDerivatives 4.0 International (CC BY-NC-ND 4.0) License. 